\title{
Biomechanical Analysis of Different Knee Prosthesis Biomaterials Using Fem
}

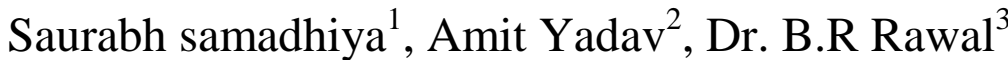 \\ ${ }^{1,2}$ Research Scholar, Department of Mechanical Engineering, S. G.S.I.T.S, Indore, MP, India \\ ${ }^{3}$ Assistant Professor, Department of Mechanical Engineering, S.G.S.I.T.S, Indore, MP, India
}

\begin{abstract}
Metal alloys have been the materials of choice since the start of orthopedic surgery. Orthopedic materials must fulfill the mechanical, biological and physical necessities of their proposed utilization. Knee joint is the most complex joint in human body gets the discriminating loads in different moving conditions. Accordingly the material utilized for knee implant assumes exceptionally essential part for long survival of knee prosthesis. The materials that are utilized as biomaterials incorporate polymers, metals, ceramics, and composites. Out of those materials cobalt-chromium alloys, titanium alloys, stainless steel and Ultra high molecular weight polyethylene are most usually utilized biomaterials for knee implants. The objective of this paper is to prepare 3D CAD model of prosthetic knee joint from available literature and study the distribution of von-mises stresses, contact pressure, total deformation and in the same by assigning it the different combination of biomaterials for femoral and tibial components. $3 D$ modeling software PRO ENGINEER 5.0 is used for $3 D$ modeling of knee implant and finite element analysis software ANSYS 12.0 is used for numerical estimation of von-mises stresses and contact pressure. The aim is to find out the FEM results considering different flexion angles of knee joint for different biomaterials compare the results and find out the best biomaterial for knee implant design for total knee replacement.
\end{abstract}

Keywords: Biomaterials, FEA (Finite Element Analysis), prosthesis, TKR (Total knee replacement), UHMWPE (Ultra High Molecular Weight Polyethylene), von-misses stress.

\section{Introduction}

The knee joint plays a very important role in human locomotion. Its structure and time behavior during different types of motion show full adaptation of the knee to its required function. The knee joint is the largest and most heavily-loaded joint of human body. The knee involves the largest bones of the human skeleton - the tibia and femur. The patella is an important component of knee, especially in the extended position of the joint. The lateral and medial meniscus constitutes the articular surface of the tibia bone.

Degenerative arthritis of the knee joint is the disease that affects the line cartilage of the tibia and the femur. It causes severe pain and may require a replacement surgery of the affected knee with artificial components. Artificial joints should satisfy certain design requirements; they should be ergonomical and biocompatible. During activation stresses are developed at the interface of joint. This in turn dictates the performance of the joint. The intensity of the stresses developed depends on several factors. To ensure the stress intensity, it is important to optimize the design of prosthetic knee joint. In this regard, FEM the most powerful numerical tool can be used to optimize the design [3]. The materials that are utilized as biomaterials assume the essential part in long survival of knee implants. Biomaterials must fulfill the mechanical, biological, and physical prerequisites of their expected utilization. Throughout day by day exercises knee implant may experience mechanical forces that have a tendency to push, pull, twist or reason its parts to rub together. These forces can result in the implant to break or wear out over the time. The mechanical properties of biomaterials can best be depicted by its modulus of elasticity, yield strength, ultimate tensile strength and elongation to failure. The materials are additionally subjected to numerous common chemicals inside the body. Despite the fact that ordinary, some of these chemicals may have a tendency to corrode few materials. In order for an implant to perform under these conditions, it must be made out of materials that can withstand these forces and chemicals. Whether an implant is intended to replace a joint, or help to repair a fracture, a few physical and biological qualities are critical when selecting the material for the implant.

The main objective of the paper is to develop a three dimensional solid model of prosthetic knee joint and Studied the nature of stresses and contact pressure between the components of knee prosthesis at different flexion angles of the knee. We studied the nature of stresses with different biomaterials with the use of finite element analysis and find out the best suited biomaterial for knee prosthesis. Pro/Engineer 5.0 was used for solid modeling of knee implant components. Finite element analysis of knee prosthesis using different biomaterials was carried out in analysis software ANSYS 12.0 by applying the load at various moving conditions. 


\subsection{Biomaterials}

\section{Material And Methods}

The materials that are used as biomaterials include polymers, metals, ceramics and composites. The metals used as biomaterials include titanium alloys, cobalt-chromium alloys, and stainless steels. In polymers UHMWPE (ultra high molecular weight polyethylene) is most commonly used biomaterial. More recently ceramics demonstrated great promise for replacing metals in total knee replacement with the chief benefits of ceramics is their superior wear properties. In this study biomechanical analysis of titanium alloys, cobaltchromium alloys, stainless steels and UHMWPE have been carried out using FEM and compare the results. Materials used for manufacturing the femoral component of implant are Ti6Al4V alloy, Co-Cr-Mo alloy, SS 316L alloy and oxidized zirconium and the commonly used material for manufacturing the linear insert now a days is UHMWPE (ultra high molecular weight polyethylene). The material properties that are being used for the analysis are mentioned in table 1.

\begin{tabular}{|l|c|c|c|c|c|}
\hline Material & $\begin{array}{c}\text { Density } \\
\left(\mathrm{Kg} / \mathrm{m}^{\wedge} 3\right)\end{array}$ & $\begin{array}{c}\text { Young's Modulus } \\
(\mathrm{Pa})\end{array}$ & $\begin{array}{c}\text { Poisson's } \\
\text { Ratio }\end{array}$ & $\begin{array}{c}\text { Yield Strength } \\
(\mathrm{Pa})\end{array}$ & $\begin{array}{c}\text { Ultimate Strength } \\
(\mathrm{Pa})\end{array}$ \\
\hline UHMWPE & 930 & $6.90 \mathrm{E}+08$ & 0.29 & $2.10 \mathrm{E}+07$ & $4.80 \mathrm{E}+07$ \\
\hline Ti6Al4V & 4430 & $1.15 \mathrm{E}+11$ & 0.342 & $8.80 \mathrm{E}+08$ & $9.50 \mathrm{E}+08$ \\
\hline CoCrMo & 8300 & $2.30 \mathrm{E}+11$ & 0.3 & $6.12 \mathrm{E}+08$ & $9.7 \mathrm{E}+08$ \\
\hline 316L SS & 8000 & $1.97 \mathrm{E}+11$ & 0.3 & $2.80 \mathrm{E}+08$ & $6.35 \mathrm{E}+08$ \\
\hline ZrO2 & 6040 & $2.1 \mathrm{E}+11$ & 0.3 & $9 \mathrm{E}+08$ & $2 \mathrm{E}+09$ \\
\hline
\end{tabular}

Table.1. Properties of different bio compatible materials widely used for prosthesis

\subsection{Methodology}

2.2.1 CAD Modeling

The geometry of prosthesis has a significant influence in its performance therefore need of adopting the standard procedure to model the prosthesis is required. Pro/engineer is a computer graphics system for modeling various mechanical designs and for performing related designs and manufacturing operations. Pro/engineer is a feature based parametric solid modeling system with many extended design and manufacturing applications. As a comprehensive CAD/CAM/CAE system, covering many aspects of mechanical design, analysis and manufacturing, pro/engineer represents the leading edge of CAD/CAM/CAE technology. The geometrical models were developed by using PRO-E 5.0 Software after referring the design standards prescribed by $\mathrm{G}$ Mallesh et al 2012.

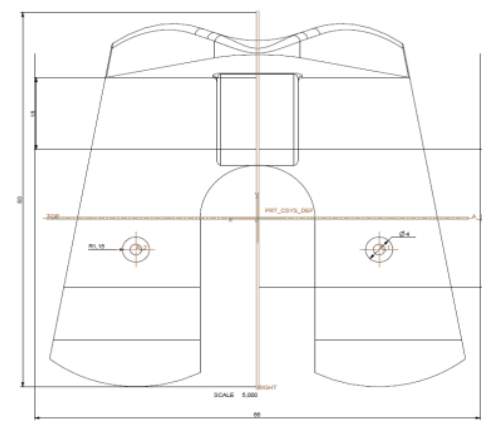

Fig.1. 2D model of femur

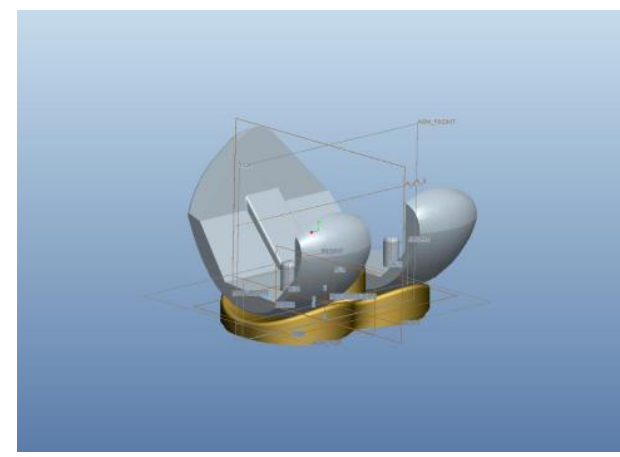

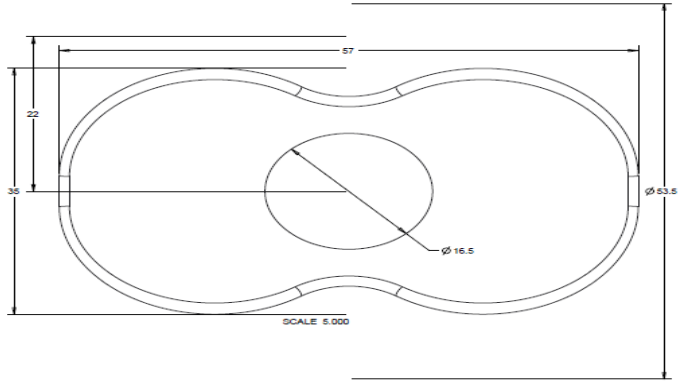

Fig.2. 2D MODULE OF TIBIA

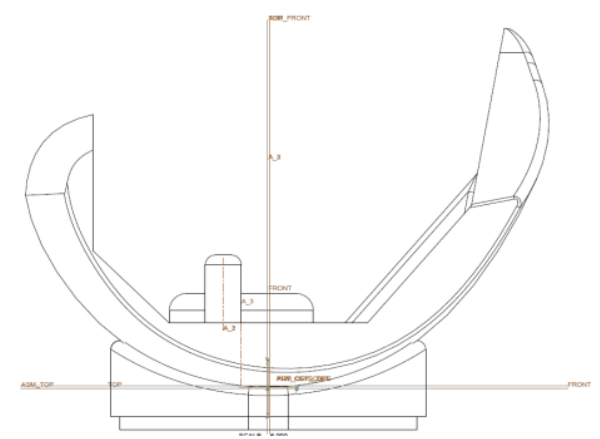

Fig.3. 3D and 2D model of prosthetic knee joint 
2.2.2. FEM analysis of knee prosthesis using different biomaterials

\subsubsection{FEM analysis when knee is in straight position ( $\left(0^{\circ}\right.$ flexion)}

FEM analysis of prosthetic knee joint, when knee is in straight position was carried out in ANSYS 12.0. Analysis performed for different combination of biomaterials. After Cad Modeling the file is converted into IGES format and imported to the ANSYS 12.0 Environment, and then the solid model is assigned with the material properties and next secernated into smaller units so called Meshing, Dividing the component assembly into finite no of elements.

\subsubsection{Mesh Convergence Test}

A check point is tested on the assembly by using mesh convergence test in order to simplify and justify the analysis result. In this process the stress level is tested on assembly by taking different size of element during meshing.

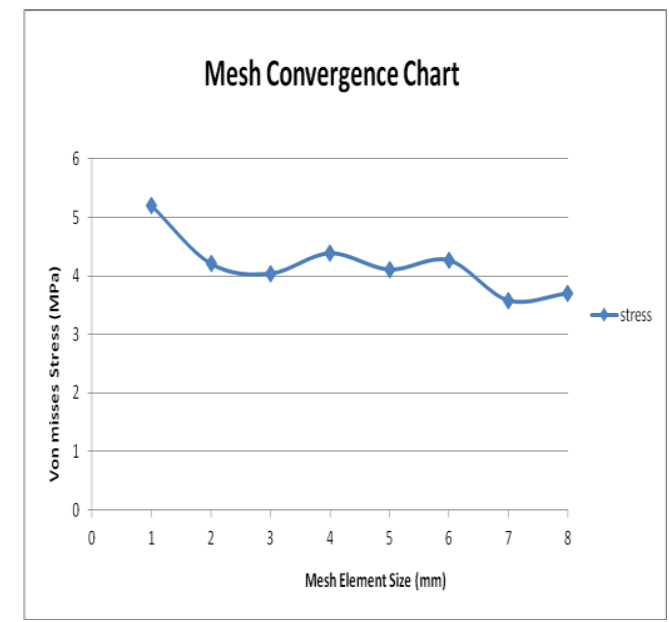

Fig.4. Mesh element size convergence test

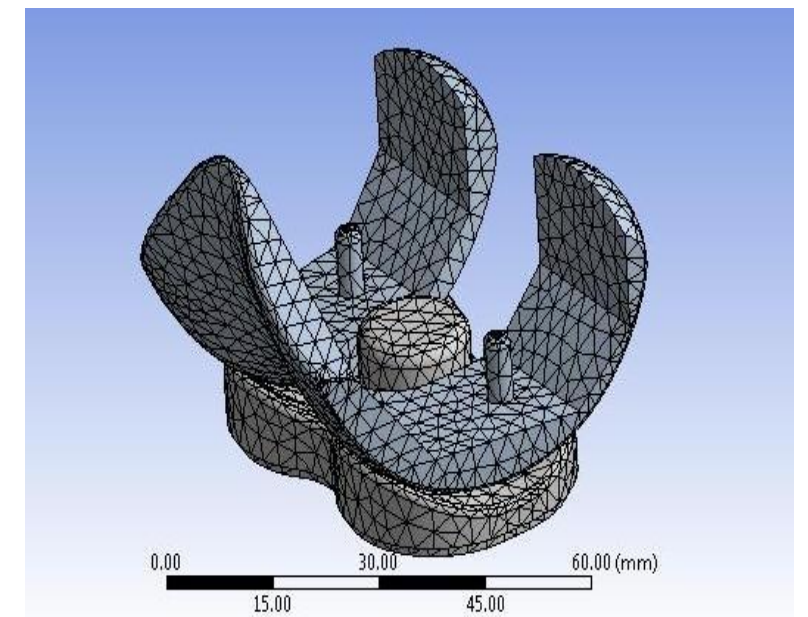

Fig.5. Meshed Knee Prosthesis Model

Meshing of the model was done after completing the mesh convergence test and defining the material collectors and assigning the materials for each of the component. Tetrahedral elements were used for all the components. Tetrahedral elements better approximate the shape with minimal error as compared to brick elements. According to the mesh convergence test Size of the tetrahedral element was $3 \mathrm{~mm}$ for all the components of knee prosthesis and a total no. of 23273 nodes and 13575 elements were generated after the meshing. Meshed knee model is shown in fig. 5.

\subsubsection{Defining Interfaces}

Various types of interfaces are available in ANSYS 12.0 but one of them which are used is:

- Frictional Contact: Characteristics of this contact are that the friction considered between two meting surfaces and it required some value of coefficient of friction.

Frictional contact was considered between femoral component and tibial poly. Values of coefficient of friction were defined as Ti6Al4V- 0.13, SS 316L- 0.12, Co-Cr-Mo- 0.07, ZrO2- 0.02-0.07.

\subsubsection{Boundary Conditions}

Load was applied in the form of force. According to ISO 14243-1, axial load is one which acts while standing and thus needs to be applied. According to ISO 14243-1 maximum load should be applied for testing the prosthesis. In this study we have tested the prosthesis at various loads gradually increasing from $600 \mathrm{~N}$ to $5000 \mathrm{~N}$ when leg is in straight position. $5000 \mathrm{~N}$ is the maximum load which is approximately 8 body weights considering average weight of an individual to be $60-65 \mathrm{~kg}$. We have checked the stress pattern with increasing load on the prosthesis. The tibial poly was constrained in all degrees of freedom at its lower surface and compressive load $600-5000 \mathrm{~N}$ were applied to the femoral component at the bearing points. 

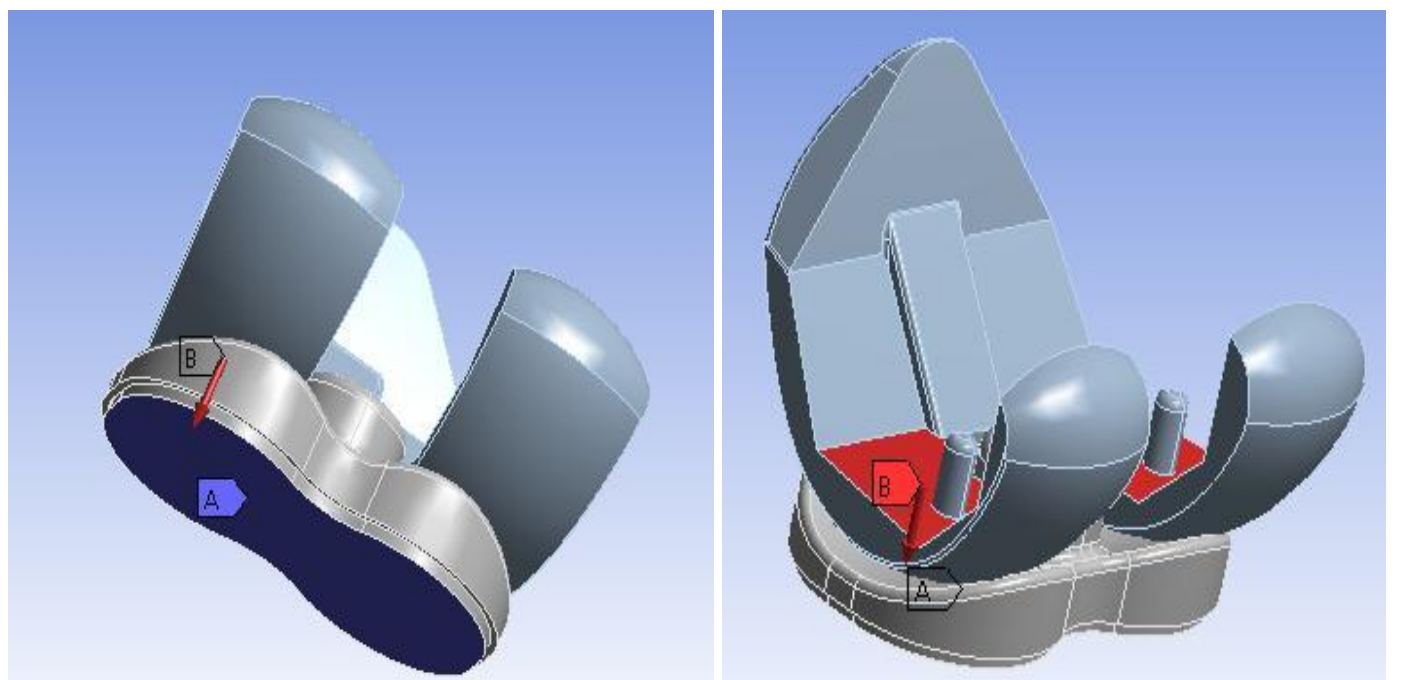

Fig.6. Boundary Conditions- fixed support and direction of load

\subsection{FEM Results}

Prosthetic knee model was analyzed at 0 degree flexion (when knee is in straight position) at the load 600-5000 $\mathrm{N}$ for various biomaterials. In ANSYS the model can be viewed in various forms and judged by different parameters. In this case three major parameters are Von mises stress, total deformation and contact pressure. Analysis was done for four biomaterials Ti-6Al-4V, Co-Cr-Mo, SS 316L and, $\mathrm{ZrO} 2$. Tibial poly was however made of UHMWPE in all the cases. Comparison of the peak values of von-mises stress, total deformation, and contact pressure of different biomaterials at maximum $5000 \mathrm{~N}$ shown in table 2. The results are also evaluated for varying load and are discussed in conclusion.

Table.2. Comparison of prosthesis made of different materials

\begin{tabular}{|l|l|c|c|}
\hline \multicolumn{1}{|c|}{ Material } & Von-mises stress & Total Deformation & Contact pressure \\
\hline Ti-6Al-4V & 33.352 & 0.119 & 46.011 \\
\hline Co-Cr-Mo & 38.65 & 0.133 & 46.61 \\
\hline SS 316L & 34.45 & 0.12 & 46.14 \\
\hline ZrO2 & 40.502 & 0.137 & 46.787 \\
\hline
\end{tabular}

Following results were observed when load applied from $600 \mathrm{~N}-5000 \mathrm{~N}$. The values of different parameters are showing in figures and tables blow.

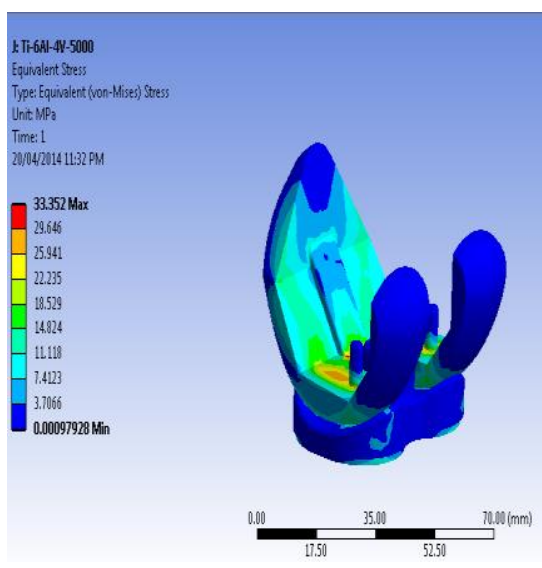

(a)

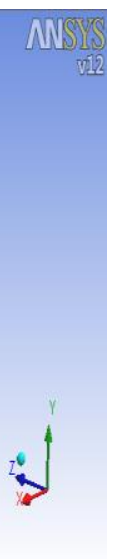

Fig.7. (a) Von-mises stress distribution at $5000 \mathrm{~N}$ (b) Graphical representation of Von-mises stress between

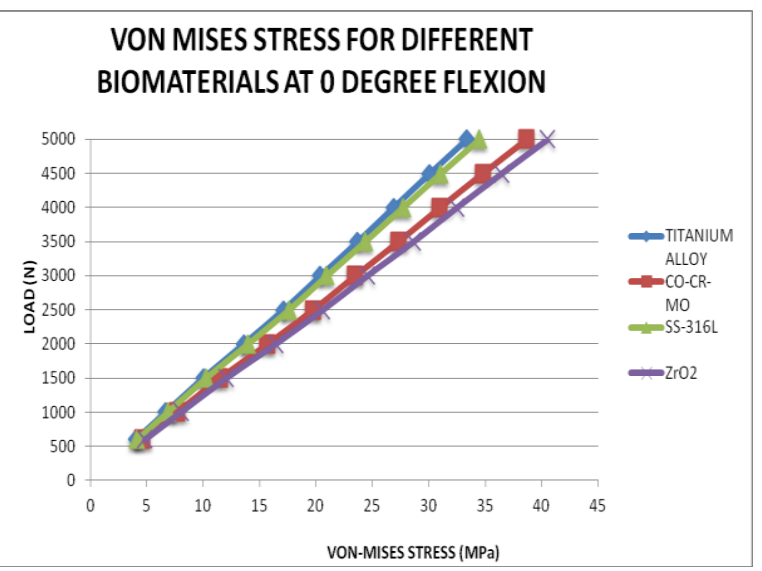

(b)

Prosthetic biomaterials 
Table.3. Comparison of Von-mises stress for different biomaterials

\begin{tabular}{|c|c|c|c|c|}
\hline Load $(\mathrm{N})$ & \multicolumn{3}{|c|}{ Von-mises Stress (MPa) } \\
\hline & Ti-6Al-4V & Co-Cr-Mo & SS 316L & 4.14 \\
\hline 600 & 4.03 & 4.63 & 6.85 & 8.622 \\
\hline 1000 & 6.68 & 7.67 & 10.25 & 12.029 \\
\hline 1500 & 10.006 & 11.5 & 13.96 & 16.403 \\
\hline 2000 & 13.595 & 15.7 & 17.59 & 20.58 \\
\hline 2500 & 17.112 & 19.73 & 20.93 & 24.522 \\
\hline 3000 & 20.379 & 23.47 & 24.33 & 28.623 \\
\hline 3500 & 23.681 & 27.29 & 27.69 & 32.47 \\
\hline 4000 & 26.857 & 30.97 & 31.03 & 36.432 \\
\hline 4500 & 30.065 & 34.76 & 34.45 & 40.502 \\
\hline 5000 & 33.352 & 38.65 & & \\
\hline
\end{tabular}

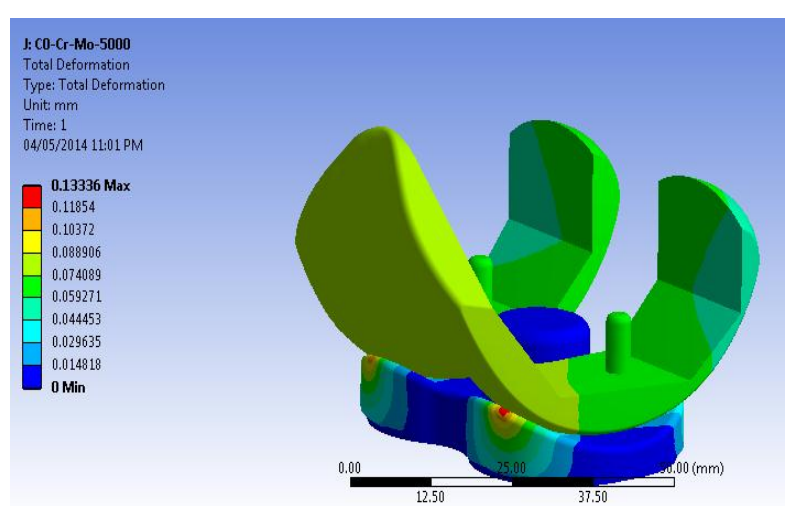

(b)

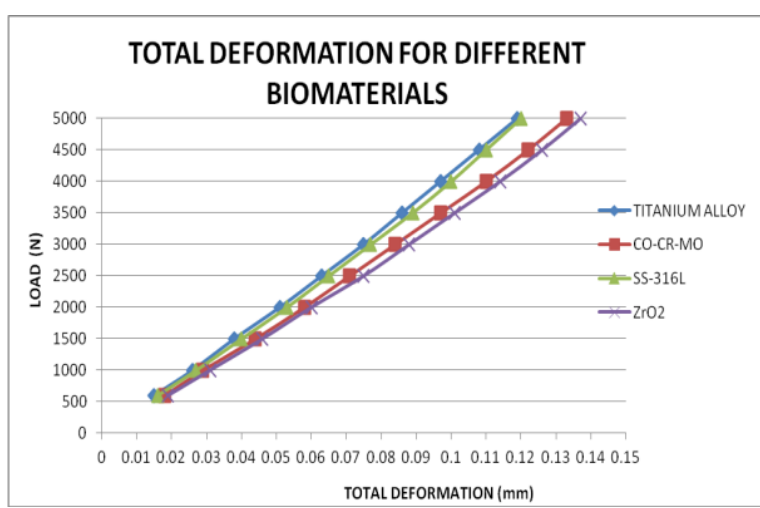

(d)

Fig.8. (c) Total deformation contour at $5000 \mathrm{~N}$ (d) Graphical representation of Total deformation between Prosthetic biomaterials

Table.4. Comparison of Total deformation for different biomaterials

\begin{tabular}{|c|c|c|c|c|}
\hline Load $(\mathrm{N})$ & \multicolumn{3}{|c|}{ Total deformation $(\mathrm{mm})$} \\
\hline & Ti-6Al-4V & Co-Cr-Mo & \multicolumn{2}{|c|}{ SS 316L } \\
\hline 600 & 0.015 & 0.018 & 0.016 & 0.019 \\
\hline 1000 & 0.026 & 0.029 & 0.027 & 0.031 \\
\hline 1500 & 0.038 & 0.044 & 0.04 & 0.046 \\
\hline 2000 & 0.051 & 0.058 & 0.053 & 0.065 \\
\hline 2500 & 0.063 & 0.071 & 0.077 & 0.075 \\
\hline 3000 & 0.075 & 0.084 & 0.089 & 0.101 \\
\hline 3500 & 0.086 & 0.097 & 0.1 & 0.114 \\
\hline 4000 & 0.097 & 0.11 & 0.11 & 0.126 \\
\hline 4500 & 0.108 & 0.122 & 0.12 & 0.137 \\
\hline
\end{tabular}

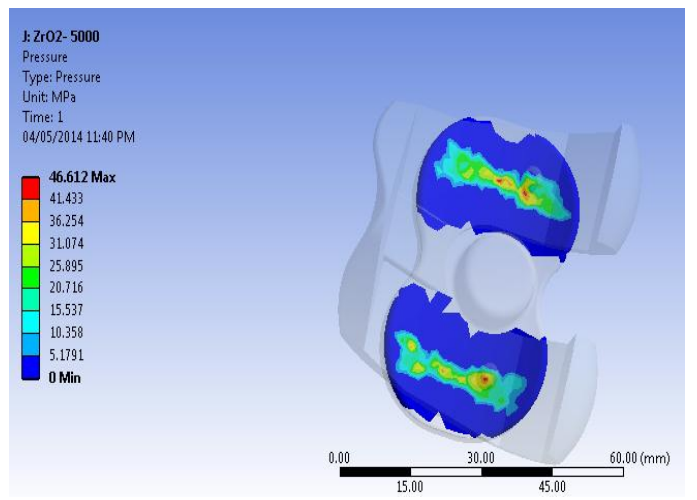

(e)

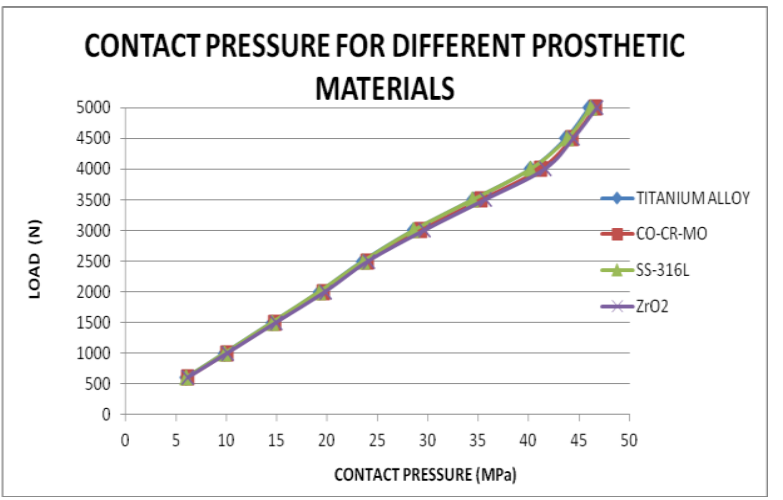

(f)

Fig.9. (e) Contact pressure contour at $5000 \mathrm{~N}$ (f) Graphical representation of contact pressure between Prosthetic biomaterials 
Table.5. Comparison of Contact pressure for different biomaterials

\begin{tabular}{|c|c|c|c|c|}
\hline \multirow{2}{*}{$\begin{array}{l}\text { Load } \\
\text { N) }\end{array}$} & \multicolumn{5}{c|}{ Contact pressure (MPa) } \\
\hline & Ti-6Al-4V & Co-Cr-Mo & SS 316L & ZrO2 \\
\hline 600 & 6.02 & 6.13 & 6 & 10.190 \\
\hline 1000 & 9.82 & 10.03 & 9.82 & 14.969 \\
\hline 1500 & 14.53 & 14.83 & 14.53 & 19.827 \\
\hline 2000 & 19.223 & 19.63 & 23.59 & 24.106 \\
\hline 2500 & 23.543 & 23.95 & 28.55 & 29.654 \\
\hline 3000 & 28.564 & 29.29 & 34.43 & 35.694 \\
\hline 3500 & 34.441 & 35.29 & 40.18 & 41.615 \\
\hline 4000 & 40.194 & 41.16 & 43.82 & 44.446 \\
\hline 4500 & 43.695 & 44.29 & 46.14 & 46.787 \\
\hline 5000 & 46.011 & 46.61 & & \\
\hline
\end{tabular}

\subsubsection{FEM analysis at different flexion angles of knee joint}

Knee implant was analyzed for different flexion angles of knee with different biomaterials. From the perspective of this problem, pre-processing (Material section, meshing and contact definition) for FEA analysis at different flexion angles is same as performed in section 2.2.2.1.1 and 2.2.2.1.2. Thus boundary condition is only the main issue for this case. Three dimensional model of the knee joint implant with $15^{\circ}, 30^{\circ}, 45^{\circ}, 60^{\circ}$ and $70^{\circ}$ flexion angles were imported and analyzed using ANSYS 12.0 software.

\subsubsection{Boundary Conditions}

Load was applied on the femoral component in the form of force. FEA analysis was carried out at $15^{\circ}$, $30^{\circ}, 45^{\circ}, 60^{\circ}$ and $70^{\circ}$ flexion of the knee. Load $2500 \mathrm{~N}$ was considered, which approximately 4 body weights considering average weight of individual to be $60-65 \mathrm{~kg}$. Vertical components of $2500 \mathrm{~N}$ at different flexion angles were find out and applied vertically downward to the upper surface of the femoral component, tibial poly was constrained in all degrees of freedom at its lower surface. Mesh size and interfaces are same as define above in FEM analysis of implant when knee is in straight position. FEM analysis at different degrees of flexion was carried out for all for biomaterials. Boundary conditions are shown in figure.10.

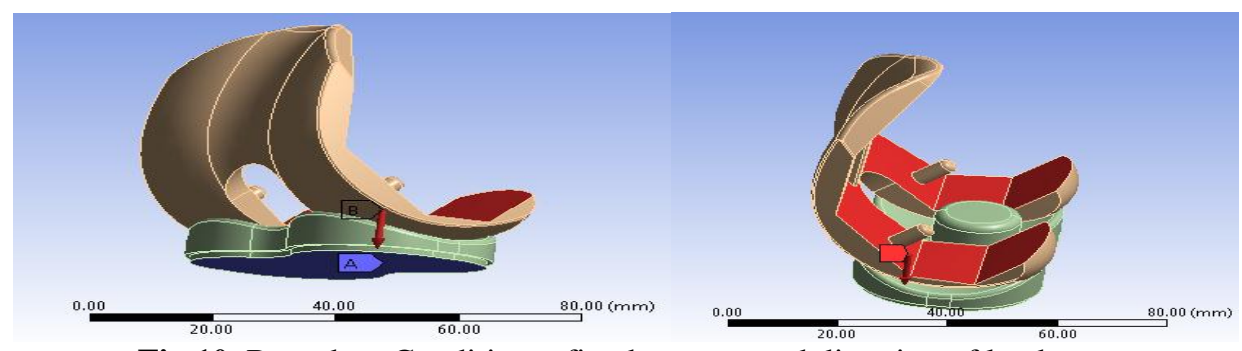

Fig.10. Boundary Conditions- fixed support and direction of load

\subsection{FEM Results}

3D Cad model of knee implant assembly at $15^{\circ}, 30^{\circ}, 45^{\circ}, 60^{\circ}$ and $70^{\circ}$ were imported in ANSYS 12.0 in IGES format and analysis was carried out for four different materials with combination of UHMWPE. The results were found out in the form of von-mises stress, total deformation and contact pressure at each degree of flexion shown in figures blow.

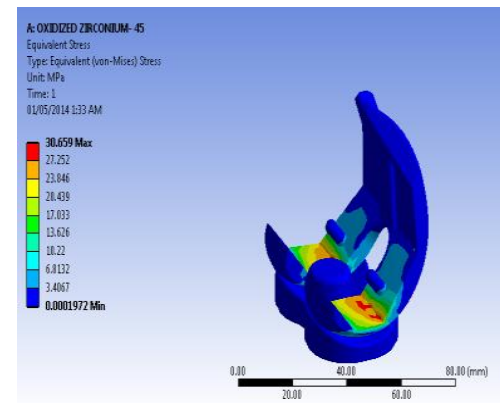

(a)

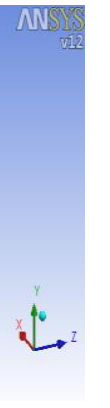

Fig.11. (a) Von-mises stress distribution at $45^{\circ}$ flexion

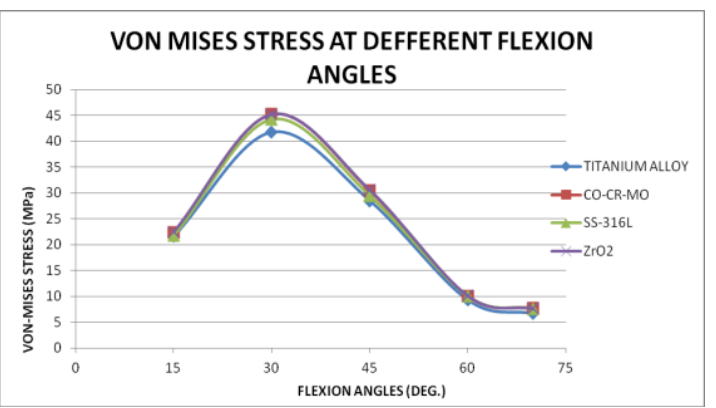

(b)

Between Prosthetic biomaterials 
Table.6. Comparison of von-mises stress between different biomaterials at different flexion angles

\begin{tabular}{|c|c|c|c|c|}
\hline $\begin{array}{c}\text { Flexion angles (Deg.) } \\
\text { Flexion angles (Deg.) }\end{array}$ & \multicolumn{3}{|c|}{$\begin{array}{c}\text { Von-mises stress (MPa) } \\
\text { Von-Mises Stress (MPa) }\end{array}$} \\
\hline & Ti-6Al-4V & Co-Cr-Mo & SS 316L & 22.512 \\
\hline $15^{\circ}$ & 21.567 & 22.391 & 21.709 & 45.251 \\
\hline $30^{\circ}$ & 41.749 & 45.212 & 44.256 & 30.659 \\
\hline $45^{\circ}$ & 28.517 & 30.447 & 29.502 & 10.158 \\
\hline $60^{\circ}$ & 9.304 & 10.075 & 10.02 & 7.646 \\
\hline $70^{\circ}$ & 6.6507 & 7.664 & 7.564 & \\
\hline
\end{tabular}

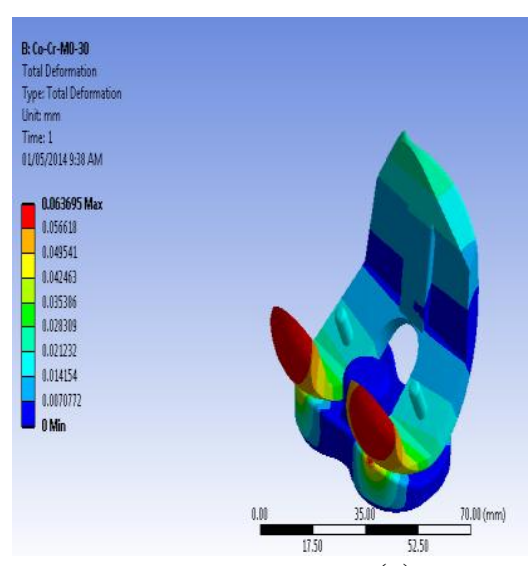

(c)

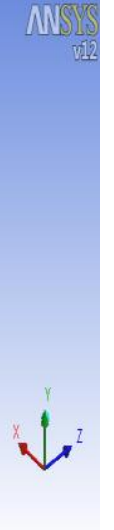

Fig.12. (c) Total deformation contour at $30^{\circ}$ flexion (d) Graphical representation of Total deformation Between Prosthetic biomaterials

Table.7. Comparison of Total deformation between different biomaterials at different flexion angles

\begin{tabular}{|c|c|c|c|c|}
\hline \multirow{2}{|c|}{$\begin{array}{l}\text { Flexion angles } \\
\text { (Deg.) }\end{array}$} & \multicolumn{4}{|c|}{ Total deformation (mm) } \\
\hline & Ti-6Al-4V & Co-Cr-Mo & SS 316L & ZrO2 \\
\hline $15^{\circ}$ & 0.0461 & 0.04287 & 0.0425 & 0.04331 \\
\hline $30^{\circ}$ & 0.07803 & 0.06369 & 0.0633 & 0.0671 \\
\hline $45^{\circ}$ & 0.1095 & 0.08107 & 0.08156 & 0.0852 \\
\hline $60^{\circ}$ & 0.0237 & 0.02168 & 0.0199 & 0.0225 \\
\hline $70^{\circ}$ & 0.0188 & 0.02085 & 0.0188 & 0.0224 \\
\hline
\end{tabular}

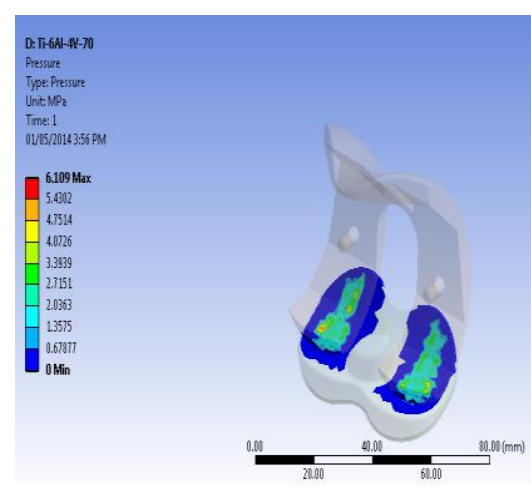

(e)

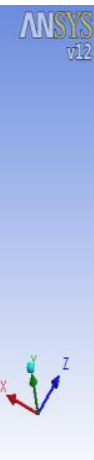

Fig.13. (e) Contact pressure distribution at $70^{\circ}$ flexion (f) Graphical representation of Contact pressure Between Prosthetic biomaterials

Table.8. Comparison of Contact pressure between different biomaterials at different flexion angles

\begin{tabular}{|c|c|c|c|c|}
\hline Flexion angles (Deg.) & \multicolumn{4}{|c|}{ Contact pressure (MPa) } \\
\hline & Ti-6Al-4V & Co-Cr-Mo & SS 316L & 25.729 \\
\hline $15^{\circ}$ & 25.069 & 25.644 & 25.333 & 19.008 \\
\hline $30^{\circ}$ & 18.082 & 18.549 & 18.017 & 14.734 \\
\hline $45^{\circ}$ & 13.025 & 14.59 & 14.002 & 10.098 \\
\hline $60^{\circ}$ & 9.957 & 9.8805 & 9.3318 & 6.0111 \\
\hline $70^{\circ}$ & 6.109 & 5.8311 & 5.746 & \\
\hline
\end{tabular}


2.2.2.3. Comparison between permissible and actual stress (In flexion)

Table.9. Permissible and Actual stress Comparison

\begin{tabular}{|c|c|c|c|}
\hline Material & $\begin{array}{c}\text { Yield Strength } \\
(\mathrm{MPa})\end{array}$ & $\begin{array}{c}\text { Permissible Stress } \\
(\mathrm{MPa})\end{array}$ & $\begin{array}{c}\text { Maximum Stress } \\
\text { Experienced } \\
(\mathrm{MPa})\end{array}$ \\
\hline Ti-6Al-4V & 900 & 300 & 41.749 \\
\hline Co-Cr-Mo & 525 & 175 & 45.212 \\
\hline SS 316L & 240 & $80-120$ & 44.256 \\
\hline ZrO2 & 900 & 300 & 45.251 \\
\hline UHMWPE & 52 & 20 & 9.3059 \\
\hline
\end{tabular}

From table 9, it is clear that all the materials are safe and stresses are well below the permissible value of stress.

\section{Result And Discussion}

The finite element analysis has been carried out in ANSYS 12.0 software and find out von-mises stresses, total deformation and contact pressure for different biomaterials for different conditions explained above. From the result shown in table 2 Ti-6Al-4V shows peak von mises stress of $33.352 \mathrm{MPa}$ which is lower than the other implant materials. SS $316 \mathrm{~L}$ ranks second with maximum stress value of $34.45 \mathrm{MPa}$, Co-Cr ranks third with peak stress value of $38.65 \mathrm{MPa}$ and $\mathrm{ZrO} 2$ comes last with a peak stress value of $40.502 \mathrm{MPa}$. From the results of FEA analysis when knee is in straight position in table $(3,4,5)$, von-mises stresses are continuously increases at varying load of $600 \mathrm{~N}-5000 \mathrm{~N}$. The von-mises stresses are varying from 2.5 to $4 \mathrm{MPa}$ at the load 600 to $5000 \mathrm{~N}$ and are maximum varying for $\mathrm{ZrO} 2$. At the steady state condition total deformation is higher in $\mathrm{ZrO} 2$ and $\mathrm{Co}-\mathrm{Cr}$ and comparatively less in Ti-6Al-4V and SS 316L. Contact pressure for different implant materials is nearly same, there is a minor difference in contact pressure value between all prosthesis materials. For the same contact area Prosthesis made of ZrO2-UHMWPE experienced slightly more contact pressure than the prosthesis made of other materials. Maximum von mises stress that prosthesis was experienced, when knee is in straight position with all biomaterials is far less than the permissible stress of all materials. From the finite element analysis at different degrees of flexion it is observed that stresses are extremely changed at the same load $2500 \mathrm{~N}$ is applied at all flexion angle. It is shown in table 6 that a von-mises stress increases at $15^{\circ}$ to $45^{\circ}$ but come down at $60^{\circ}$ and $70^{\circ}$. Ti-6Al-4V experienced minimum von-mises stress 41.714 among all other prosthetic bio-materials, SS $316 \mathrm{~L}$ comes second and there is a minor difference in vonmises stress value for $\mathrm{Co}-\mathrm{Cr}$ and $\mathrm{ZrO} 2$. There is a minor difference in contact pressure at each degree of flexion except $45^{\circ}$, at $45^{\circ}$ flexion Ti-6Al-4V shows less contact pressure with UHMWPE than other materials for the same contact area. The maximum von-mises stress value that UHMWPE (which is used for tibial spacer in all combination) is experiencing is 9.3059 which is lower than the permissible stress value.

\section{Conclusion}

Finite element analysis proved as one of the efficient technique for evaluation of the performance of prosthesis with different materials under day to day loading conditions. The facts can be concluded by this study and research work:

$\checkmark$ From the first study (FEM analysis when knee is in straight position) it is clear that even under extreme loading conditions the prosthesis is safe and gives good results for all selected biomaterials- Ti-6Al$4 \mathrm{~V}, \mathrm{Co}-\mathrm{Cr}, \mathrm{SS}-316 \mathrm{~L}$, UHMWPE and $\mathrm{ZrO} 2$.

$\checkmark$ Static loading (FEM analysis when knee is in straight position) of $\mathrm{ZrO} 2$ proved its performance to be not as good as other three biocompatible metallic alloys.

$\checkmark$ Loading at different flexion angles the prosthesis assembly behaves well enough with von-mises stress higher than the first case.

$\checkmark$ Contact pressure is also not having any negligible variation with different combination of biomaterials.

$\checkmark$ Knee implants made from Oxidized zirconium (ZrO2) have been introduced by Smith \& Nephew. This material has shown promising results due to its unique material properties of a metal and wear fighting capabilities of a ceramic. During FEA it performs nearly similar to rest of materials and it shows little bit high stress than other materials.

$\checkmark$ It is clear from the FEA results that the Titanium Alloys (Ti-6Al-4V) is the best material of choice for knee implant because it shows the minimum Von-mises stress at the extreme loading conditions than the other materials.

\section{Refrences}


[1] Dr. B. Ravi, Sandip Anasane, Anshul Pandey, Kapil Kumar Rathi, Nirmal Panda, “Total Knee Prosthesis: Design, Manufacture, and Testing", team tech 2007.

[2] Anurag Soni, Anoop Chawla, Sudipto Mukherjee 'Effect of muscle contraction on knee loading for a standing pedestrian in lateral Impacts" of Mechanical Engineering Indian Institute of Technology Delhi, India Paper Number 07-0458.

[3] G Mallesh et al 'Finite Element Modeling and Analysis of Prosthetic Knee Joint' International Journal of Emerging Technology and Advanced Engineering ISSN 2250-2459, Vol. 2, Issue 8, 2012.

[4] JOON PARK, Bioceramics properties characterizations and applications ISBN 978-0-387-09544-8, Springer Science, Business Media LLC, 2008.

[5] M. A. Kumbhalkar, Umesh Nawghare, Modeling and Finite Element Analysis of Knee Prosthesis with and without Implant, universal Journal of Computational Mathematics 1(2), 2013: 56-66.

[6] Vaidya SV, Ranawat CS, Aroojis A, Laud NS, Anthropometric measurements to design total knee prostheses for the Indian population J arthroplasty15, 2000, 79-85x.

[7] Tammy L. Haut Donahue, M. L. Hull, Mark M. Rashid, A Finite Element Model of the Human Knee Joint for the Study of TibioFemoral Contact, Journal of Biomechanical Engineering, Vol. 124/273, JUNE 2002.

[8] Jason p. Halloran, Anthony j petrella, explicit finite element modeling of total knee replacement mechanics, journal of biomechanics 38 (2005).

[9] Martin Kubcek, Zdenek Florian, stress strain analysis of knee joint, Engineering MECHANICS, Vol. 16, No. 5, p. 315-322, 2009.

[10] Fu Bo Cheng, Xiao Feng Ji c, Ying Lai, Three dimensional morphometry of the knee to design the total knee arthroplasty for Chinese Population, The Knee 16, 2009, 341-347.

[11] R.willing, I. Y. Kim, Quantifying the competing relationship between durability and kinematics of total knee replacements using multi Objective design optimization and validated computational models, journal of Biomechanics, 141-147, 45(2012).

[12] Yeh-Liang Hsu, Yung-Chieh Hung, Design of novel total knee prosthesis using TRIZ, Journal of Medical and Biological engineering 26(4), 2006, 177-185.

[13] Clare K. Fitzpatrick, Chadd W Clary, The role of patient, surgical, and implant design variation in total knee replacement performance, Journal of Biomechanics 45 (2012) 2092-2102. 